\title{
Effect of Inorganic Phosphate on Acridine Inhibition and Plasmid Curing in Escherichia coli
}

\author{
By H. NAKAMURA \\ Biological Institute, Faculty of Science, Konan University, Kobe 658, Japan \\ A. SUGANUMA* \\ Department of Microbiology, Kyoto Prefectural University of Medicine, \\ Kyoto 602, Japan \\ AND J. GREENBERG† \\ Palo Alto Medical Research Foundation, Palo Alto, California 9430 , U.S.A.
}

(Received 2 I February 1975; revised 26 May 1975)

\section{SUMMARY}

Some mutants and stock strains of Escherichia coli $\mathrm{KI} 2$ were sensitive to acriflavine in the presence of inorganic phosphate but were resistant to acriflavine in its absence. They mutated spontaneously to resistance to acriflavine plus phosphate. The synergistic effect of phosphate on acriflavine sensitivity was increased at high $\mathrm{pH}$ values. Genetic analysis suggested that the mutations occurred in the gene acr $A$. Electron microscopic observation suggested that the presence of acriflavine plus phosphate affected the structure of the plasma membrane and the cytoplasm under it. This structural alteration was not caused by acriflavine alone. Acridine orange plus phosphate can more effectively eliminate the plasmid F8-gal ${ }^{+}$than acridine orange alone.

\section{INTRODUCTION}

Acridines eliminate some plasmids carried by bacteria (Hirota, I960; Nakamura, 1974). Their efficiency, however, is determined by alleles of the gene $a \mathrm{cr} A$, which is located between proC and purE on the Escherichia coli chromosome (Nakamura, 1968, 1974; Nakamura, Tojo \& Greenberg, 1975). This gene is involved in the organization of plasma membrane (Nakamura \& Suganuma, 1972) by determining biosynthesis of a membrane protein (unpublished data). We presume that the principal point of action of acridines is in the plasma membrane and that it is physically and physiologically associated with the plasmid and chromosome.

During the course of these investigations it was observed that some but not all strains resistant to acriflavine (AF), an acridine dye, were sensitive to AF plus phosphate, and that plasmid elimination by acridines was stimulated by phosphate. The present paper deals with these observations.

* Present address: The Maiduru National Hospital, Maiduru Kyoto-fu 625, Japan. U.S.A.

$\dagger$ Present address: U.S. Public Health Service, Center for Disease Control, Atlanta, Georgia 30333, 
Table I. Bacterial strains used

\begin{tabular}{|c|c|c|}
\hline Strain & Character* & Origin \\
\hline N43 & $\mathrm{F}^{-}:$Acr $\mathbf{A}^{-}$, Acp $^{-}$, lac, ara & w4573 \\
\hline $\begin{array}{l}\text { N544, N701, N705, N707, N709 } \\
\text { w6 }\end{array}$ & $\begin{array}{l}\mathrm{F}^{-}: \mathrm{AcrA}^{+}, \mathrm{Acp}^{-}, \text {lac, ara } \\
\mathrm{F}^{+}: \mathrm{AcrA}^{+}, \mathrm{Acp}^{-}\end{array}$ & $\begin{array}{l}\text { Independent revertants of } \mathrm{N} 43 \\
\text { Stock strain }\end{array}$ \\
\hline AB3 I I & $\mathrm{Hfr}: \mathrm{AcrA}^{+}, \mathrm{Acp}^{-}$ & Stock strain \\
\hline АВI 899 & $\mathrm{~F}^{-}: \mathrm{AcrA}^{+}, \mathrm{Acp}^{-}$ & Stock strain \\
\hline N545 & $\mathrm{F}^{-}: \mathrm{AcrA}^{+}, \mathrm{Acp}^{+}$ & Revertant of $\mathrm{N} 43$ \\
\hline WI 895 & Hfr: AcrA $^{+}$, Acp $^{+}$ & Stock strain \\
\hline HfrH & Hfr: $\operatorname{AcrA}^{+}$, Acp $^{+}$ & Stock strain \\
\hline$\chi 478$ & $\mathrm{~F}^{-}: \mathrm{AcrA}^{+}, \mathrm{Acp}^{-}$ & Stock strain \\
\hline $\mathrm{N} 2025$ & $\mathrm{~F}^{\prime}: \mathrm{F}-\mathrm{gal}^{+} \mid a c r A$ & Nakamura (1974) \\
\hline
\end{tabular}

* Symbols of phenotypes: $\mathrm{AcrA}^{-}$and $\mathrm{AcrA}^{+}$, sensitivity and resistance respectively to AF; $\mathrm{Acp}^{-}$and $\mathrm{Acp}^{+}$, sensitivity and resistance respectively to $\mathrm{AF}+$ phosphate. Symbols of genotypes are as described by Taylor \& Trotter (1972).

\section{METHODS}

Bacterial strains. These were derivatives of Escherichia coli $\mathrm{KI} 2$ and are listed in Table I. Media. Broth media PGY, L, and BTB-galactose were as described by Nakamura (I965), Lennox (1955), and Nakamura (I97I), respectively, and minimal medium $\mathrm{S}_{1^{-}}$ glucose was as described by Nakamura (I968). Medium DK consisted of $\left(\mathrm{g} / 1 \mathrm{H}_{2} \mathrm{O}\right)$ : tryptone, $10 ; \mathrm{NaCl}, 5$; glucose, $\mathrm{I}$.

For phosphate-enriched media, PGY or DK was mixed with an equal volume of $0.2 \mathrm{M}-$ phosphate buffer $\mathrm{pH} 7 \cdot 4$. As a control medium, $0.2 \mathrm{M}$-tris- $\mathrm{HCl}$ buffer $\mathrm{pH} 7.4$ or distilled water was added instead of the phosphate solution.

Crosses. General procedures for the genetic crosses were as described by Nakamura (1965).

Electron microscopy. The general procedures were as described by Nakamura \& Suganuma (1972).

\section{RESULTS}

\section{Sensitivity to AF plus phosphate}

Thirty independent spontaneous revertants of strain N43 resistant to AF were isolated and tested for sensitivity to AF + phosphate. There was a continuous distribution, rather than a small number of well-defined classes, of sensitivities to AF + phosphate. The mutants N544 (Nakamura, I968), N70I, N705, N707 and N709 were the strains most sensitive to AF + phosphate (Fig. I, $a$ to $e$ ).

Strains ABI899, $x 478$, w6, HfrH, WI 895 (Fig. I, $f$ to $j$ ) and AB3 I (Fig. 2) were stock cultures in our laboratory. Strains HfrH and WI 895 were resistant to AF both in the presence and absence of phosphate. The others were sensitive to AF+phosphate, but were resistant to AF in the absence of phosphate (Figs. I, 2).

When the strains sensitive to AF + phosphate were plated on to agar medium containing AF (I5 $\mu \mathrm{g} / \mathrm{ml}$ ) and phosphate, stable mutants resistant to AF+ phosphate appeared. The effect of AF + phosphate on one such mutant, derived from AB3II, is shown in Fig. 2.

Control experiments showed that incubation with DK medium containing phosphate alone did not kill any cells in any strain tested. It was also confirmed that the phosphate effect was not observed when other injurious agents such as streptomycin and u.v. radiation were used, so that it is probably a specific synergistic effect.

It was thought possible that the phosphate effect on sensitivity to AF was due to some 


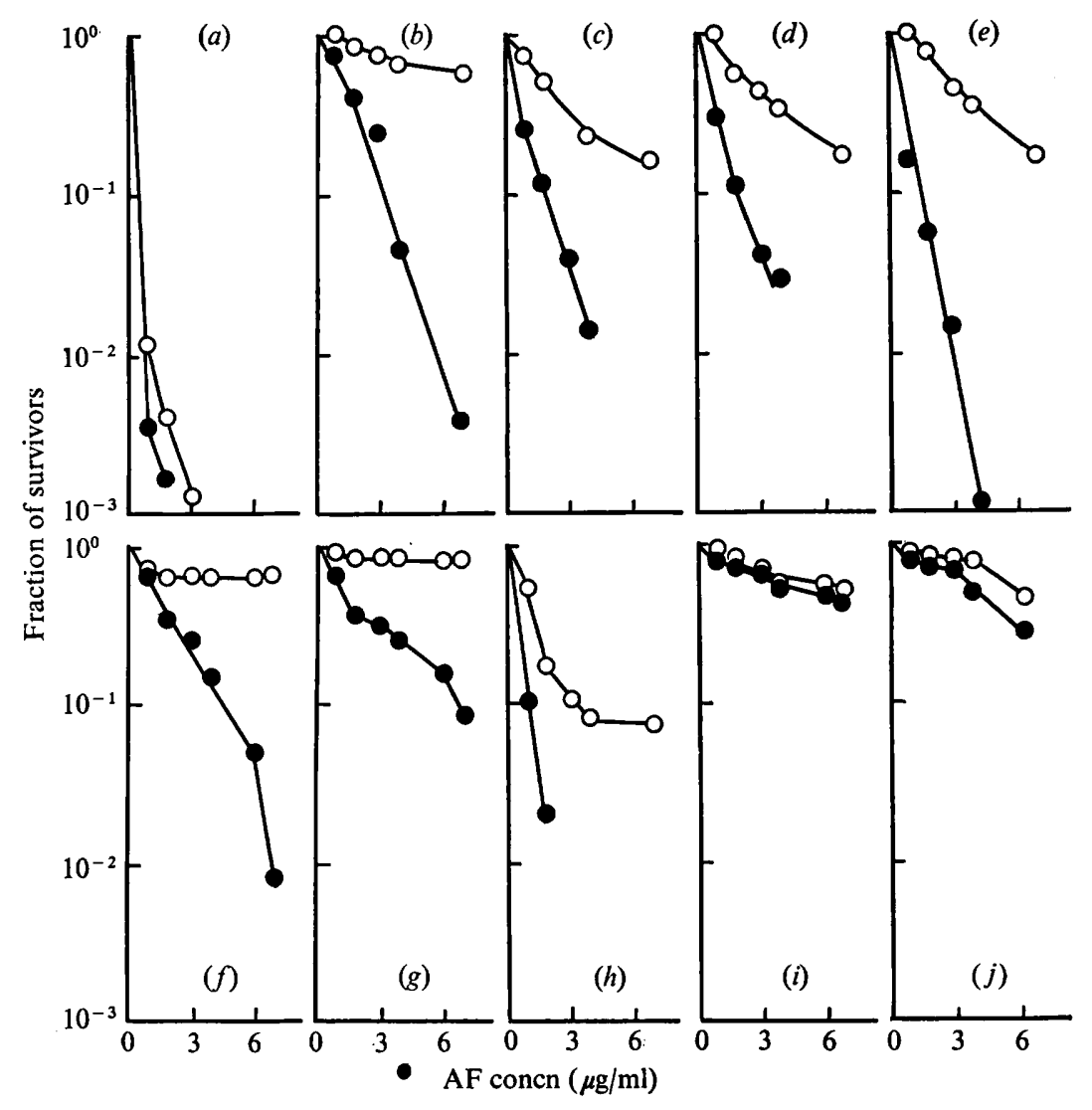

Fig. I. Survival of the various strains in AF-containing media with and without $0 \cdot 1$ M-phosphate. The bacteria were incubated in DK medium containing AF (O) and AF + phosphate (O) for $60 \mathrm{~min}$ and plated on to normal DK agar medium to determine survival. $(a) \mathrm{N} 43$; $(b) \mathrm{N} 70 \mathrm{I}$; (c) N705; (d) N707; (e) N709; (f) ABI 899; $(g) \chi 478 ;(h)$ w6; (i) HfrH; (j) WI 895.

impurity in the reagents, even though special-grade reagents were used. To test this, $\mathrm{Na}_{2} \mathrm{HPO}_{4}$ and $\mathrm{KH}_{2} \mathrm{PO}_{4}$ (special grade; Wako Pure Co., Osaka, Japan) were recrystallized nine times through redistilled water before use. Since these highly purified reagents gave the same results as the original, less pure, reagents (Fig. I), it is unlikely that the phosphate effect on the response to AF is due to impurities in the reagents.

We next attempted to examine the relationship between the phosphate concentration in the medium and the AF sensitivity of the cells. Viability was highest at $8.4 \mathrm{~mm}$-phosphate and lower at increased concentrations (Fig. 3). Without AF, viability was not affected by the phosphate concentrations used.

The phosphate effect is unlikely to be caused by an osmotic imbalance between the inside and outside of the plasma membrane, since $0 . \mathrm{I} \mathrm{M}-\mathrm{NaCl}$ (osmotically higher than $0 . \mathrm{I} \mathrm{M}$ phosphate) had no significant effect on the sensitivity of cells to AF.

The AF binding capacity of cells, which correlates with their sensitivity to AF in terms of survival and plasmid curing, is dependent upon the $\mathrm{pH}$ of the medium (Hirota, 1960; Nakamura, I966, 1967). To investigate the effect of $\mathrm{pH}$ upon the phosphate effect, N544 was inoculated into two series of AF containing PGY media, the one buffered by $0 \cdot 1 \mathrm{M}$ phosphate and the other by $0 \cdot \mathrm{I}$ M-tris- $\mathrm{HCl}$ control cultures containing no AF. After $60 \mathrm{~min}$ 


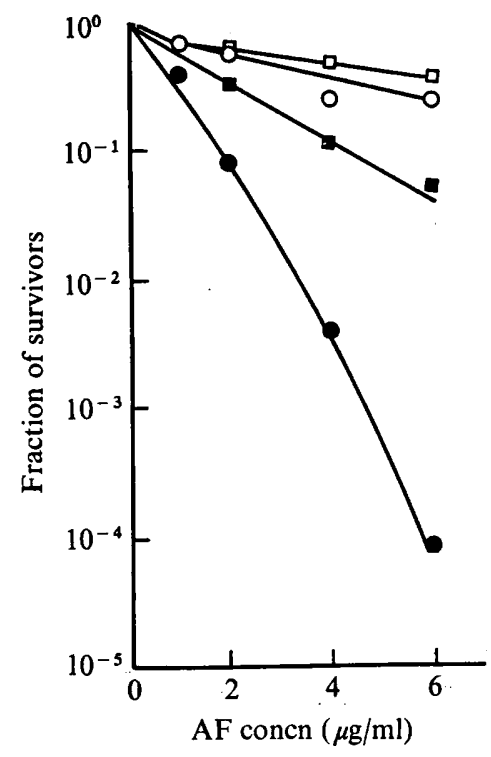

Fig. 2

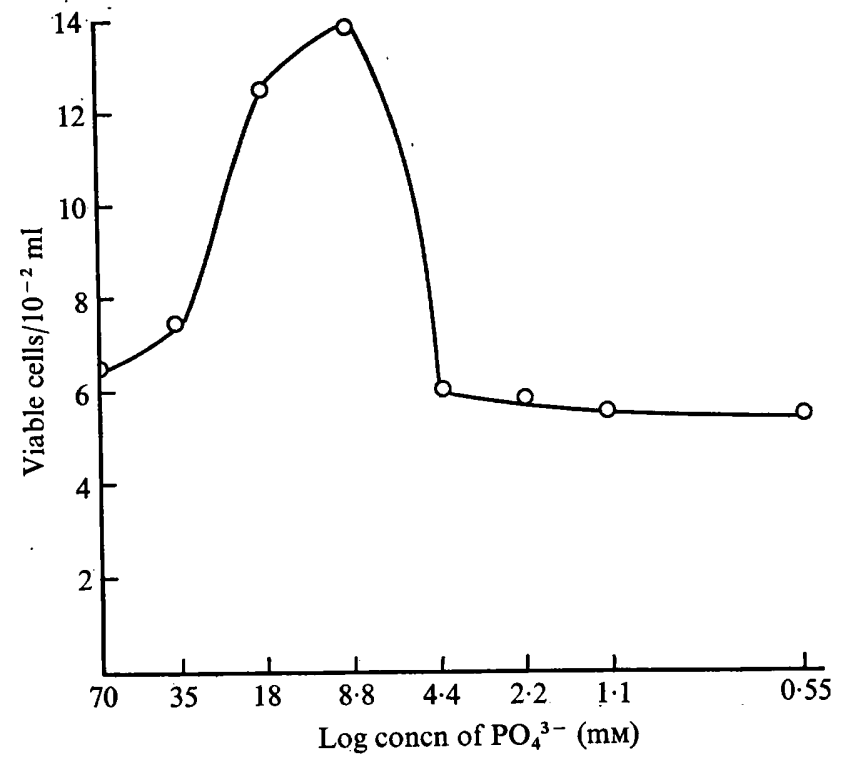

Fig. 3

Fig. 2. Mutation from sensitivity to resistance to $A F+$ phosphate in $A B 3 I I . O, O$, Strain $A B 3 I I$;

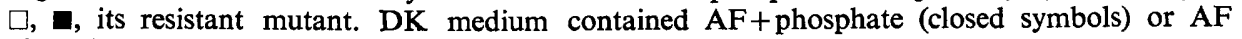
alone (open symbols). Survivors were determined as in Fig. I.

Fig. 3. Effect of phosphate concentration in the medium on AF sensitivity of N709. Medium $\mathrm{S}_{1^{-}}$ glucose was modified so as to have a series of graded phosphate concentrations $(67 \mathrm{mM}$ at maximum) and $2 \mu \mathrm{g} \mathrm{AF} / \mathrm{ml}$. Fresh cells of the strain were inoculated into these media and, after $60 \mathrm{~min}$ shaking, viable cells were counted by plating on PGY agar medium.

shaking, samples were plated on PGY medium ( $\mathrm{pH} 7 \cdot 4$ ) to count viable cells. As shown in Fig. 4, the pH-dependence of sensitivity to AF was greater when phosphate was present than when it was replaced by tris. The control experiments indicated that at high $\mathrm{pH}$ values, tris, like phosphate, acts synergistically with AF, but to a much lesser extent.

\section{Genetic analysis of sensitivity to AF plus phosphate}

In mating experiments, wI 895 was used as the donor of Acp', and N70I, N705, N707 and $\mathrm{N} 709$ as Acp ${ }^{-}$recipients. The donor strain is able to form colonies on DK agar medium (pH 7.4) containing AF ( $15 \mu \mathrm{g} / \mathrm{ml})$, both with and without the addition of phosphate. The recipients, however, can only form colonies on DK agar medium ( $\left.\mathrm{pH}_{7} \cdot 4\right)$ containing AF ( $15 \mu \mathrm{g} / \mathrm{ml}$ ) if no phosphate is added.

After $2 \mathrm{~h}$ mating of the donor and recipients, $\mathrm{lac}^{+} \mathrm{met}^{+}$and $\mathrm{ara}^{+} \mathrm{met}^{+}$recombinants were selected. The recombinants, after purification, were tested for sensitivity to AF + phosphate. As a control experiment, a cross was performed between strains wi895 (AcrA ${ }^{+} \mathrm{Acp}^{+}$) and $\mathrm{N} 43\left(\mathrm{AcrA}^{-} \mathrm{Acp}^{-}\right)$. Table 2 shows that the Acp ${ }^{+}$phenotype is closely linked to $\mathrm{lac}^{+}$ (about $80 \%$ ) and less closely to $\mathrm{ara}^{+}$(about 45 to $50 \%$ ). The linkage of $\mathrm{Acp}^{+}$to both $\mathrm{lac}^{+}$and $\mathrm{ara}^{+}$is about the same as the linkage of $a \mathrm{crA} \mathrm{A}^{+}$to these same markers (cf. WI895 $\times$ N43). Furthermore, no recombinant sensitive to AF alone appeared on selection for either $\mathrm{lac}^{+}$or $\mathrm{ara}^{+}$. 


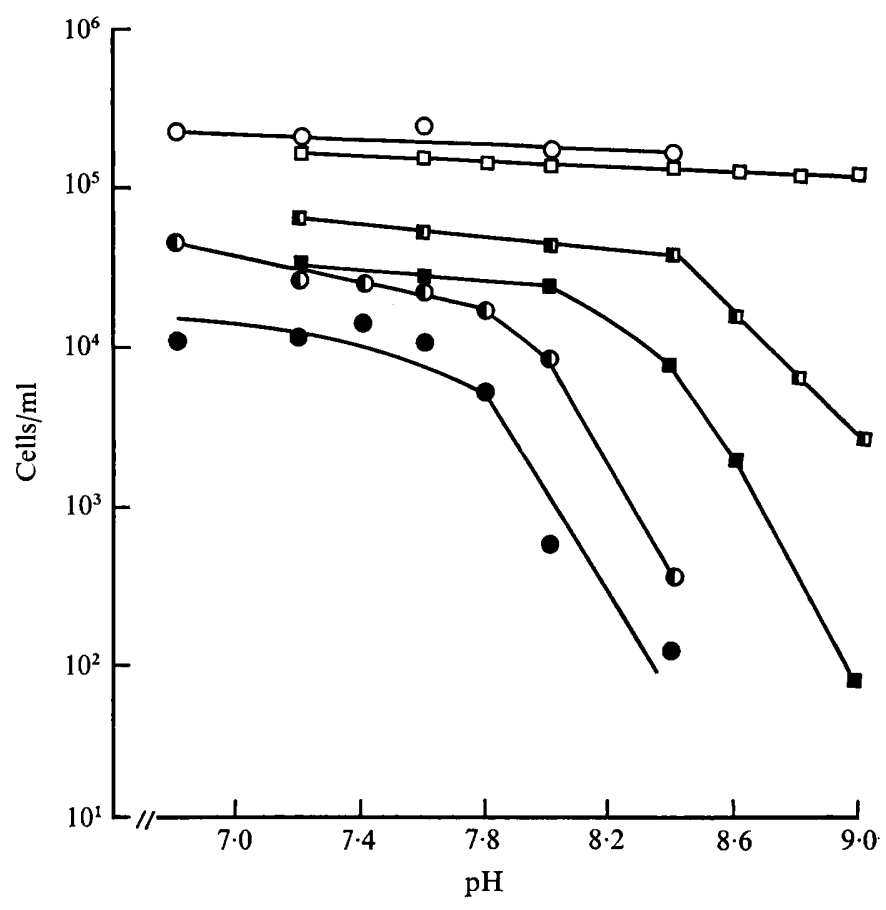

Fig. 4

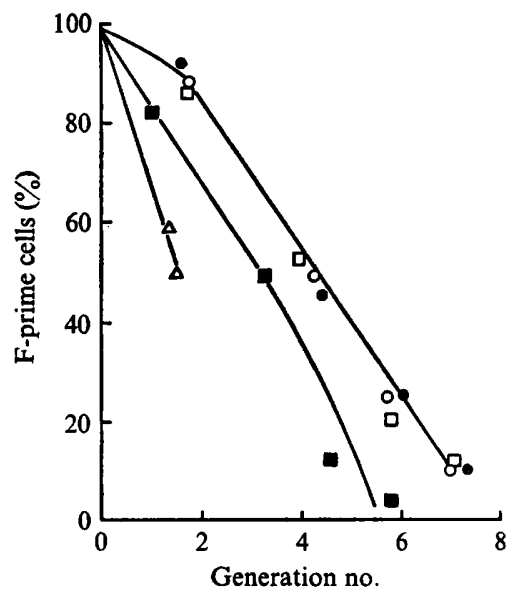

Fig. 5

Fig. 4. Effect of phosphate on the AF sensitivity at various $\mathrm{pH}$ values. PGY media were buffered by $0.1 \mathrm{M}$-phosphate (circles) and $\mathrm{O}_{\mathrm{I}} \mathrm{M}$-tris-HCl (squares). $\mathrm{O}, \square: \mathrm{No} \mathrm{AF} ; \boldsymbol{O}, \mathbf{D}, \mathrm{I} \mu \mathrm{g} \mathrm{AF} / \mathrm{ml}$; $0,2 \mu \mathrm{g} \mathrm{AF} / \mathrm{ml}$.

Fig. 5. Effect of phosphate on plasmid curing mediated by acridine in strain N2025. Cells were inoculated into PGY (pH $7 \cdot 8)$, containing acridine orange $(\mathrm{I} \mu \mathrm{g} / \mathrm{ml})$ and various concentrations of phosphate, and shaken. Samples were plated on BTB-galactose to determine the frequency of $\mathrm{Gal}^{+}$ cells. $O$, No addition of phosphate; $\square, \square, \triangle$, phosphate at concentrations of $10^{-4} \mathrm{M}_{1} \mathrm{IO}^{-3} \mathrm{M}$, $5 \times 10^{-3} \mathrm{M}$, and $10^{-2} \mathrm{M}$, respectively.

\section{Table 2. Genetic constitution of the recombinants from crosses between an Acp donor and Acp- recipients}

Exponentially growing cultures of the donor and recipient strains were mixed in the proportion I Hfr to $20 \mathrm{~F}^{-}$. After incubation for $2 \mathrm{~h}$ without shaking, the mixture was diluted and plated on the selective media, followed by purification of the recombinants. Sensitivity to AF and to AF+ phosphate was determined by point-inoculation on DK agar plates containing $15 \mu \mathrm{g} \mathrm{AF} / \mathrm{ml}$, with and without the addition of $\mathrm{O} \cdot \mathrm{I}$ M-inorganic phosphate.

\begin{tabular}{|c|c|c|c|c|c|c|}
\hline \multirow[b]{2}{*}{ Cross } & \multirow[b]{2}{*}{ Selected for } & \multirow[b]{2}{*}{$\begin{array}{l}\text { No. } \\
\text { tested }\end{array}$} & \multicolumn{4}{|c|}{ Frequency of phenotype $(\%)$} \\
\hline & & & $\operatorname{AcrA}^{+}$ & $\mathbf{A c p}^{-}$ & $\mathrm{Lac}^{+}$ & Ara ${ }^{+}$ \\
\hline WI $895 \times$ N7OI & $\mathrm{lac}^{+} \mathrm{met}^{+}$ & I 26 & 100 & 79 & 100 & $3 I$ \\
\hline WI $895 \times N 705$ & $\mathrm{lac}^{+} \mathrm{met}^{+}$ & 134 & 100 & $8 \mathrm{I}$ & 100 & 28 \\
\hline WI $895 \times N 707$ & $\mathrm{lac}^{+} \mathrm{met}^{+}$ & 150 & 100 & 82 & 100 & 28 \\
\hline WI $895 \times$ N709 & $\mathrm{lac}^{+} \mathrm{met}^{+}$ & 150 & 100 & 79 & 100 & 24 \\
\hline WI $895 \times \mathrm{N} 43$ & lac $^{+}$met $^{+}$ & 150 & 84 & - & 100 & 38 \\
\hline WI $895 \times N 705$ & $\mathrm{ara}^{+} \mathrm{met}^{+}$ & 150 & 100 & 49 & $6 I$ & 100 \\
\hline WI $895 \times N 707$ & $\mathrm{ara}^{+} \mathrm{met}^{+}$ & 150 & 100 & 45 & 57 & 100 \\
\hline WI $895 \times N 709$ & $\mathrm{ara}^{+} \mathrm{met}^{+}$ & I 50 & 100 & 49 & 63 & 100 \\
\hline WI $895 \times N 43$ & ara $^{+}$met $^{+}$ & 150 & 48 & - & 56 & $x 00$ \\
\hline
\end{tabular}



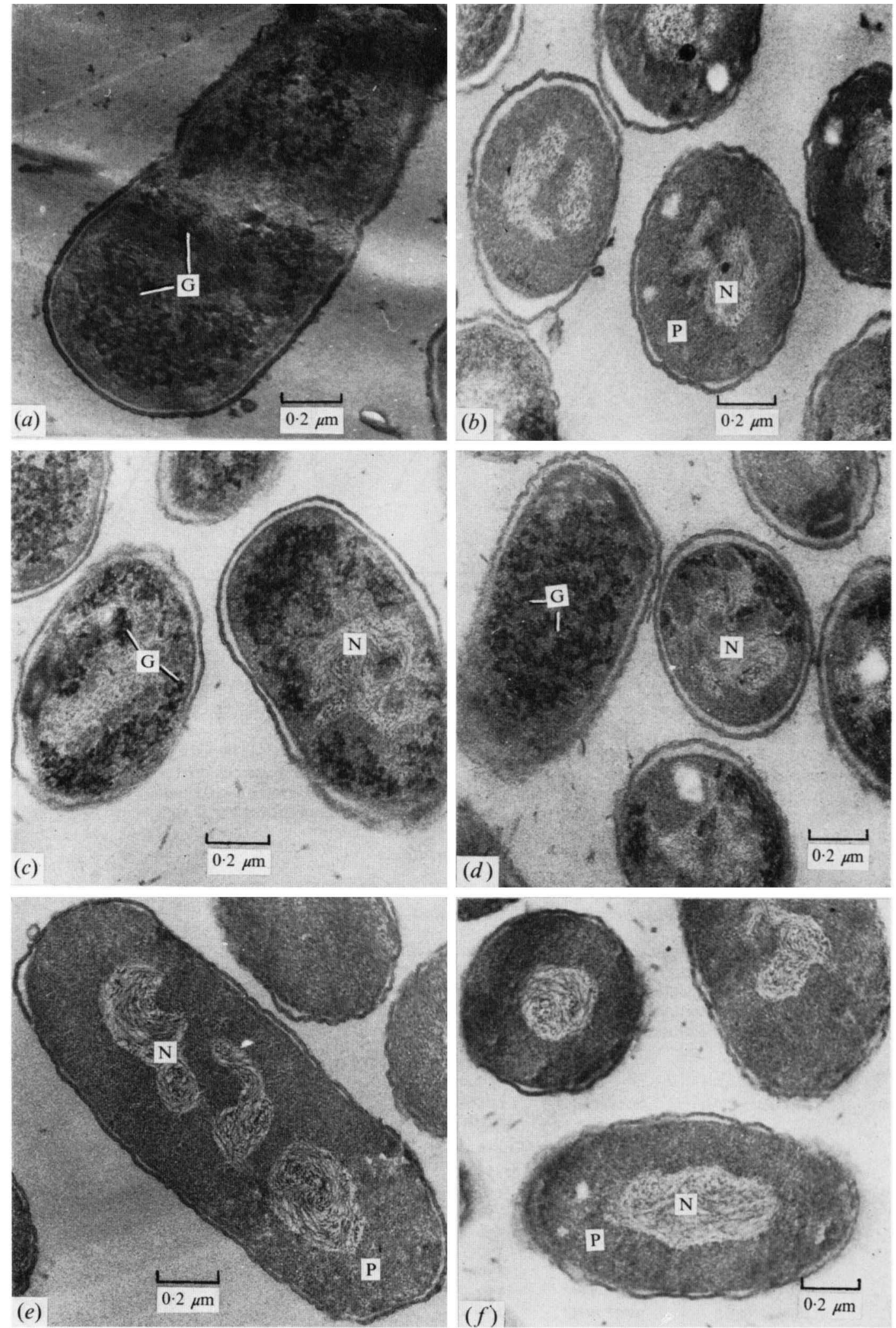

Fig. 6. Sections N544 and N545. (a) Strain N544 was incubated with PGY medium containing AF $(50 \mu \mathrm{g} / \mathrm{ml})$ and phosphate (O.I M) for $30 \mathrm{~min}$. The cytoplasm contains granular aggregates (G). (b) Strain N544 with AF (50 $\mu \mathrm{g} / \mathrm{ml})$ alone (without addition of phosphate). The cytoplasm (P) and the nucleus $(\mathrm{N})$ show normal structure. $(c),(d)$ Strain N544 treated as in $(a)$ and $(b)$, respectively. Both kinds of cells show small granular aggregates $(G)$ in the cytoplasm, but the nucleus (N) shows normal configuration. $(e),(f)$ Sections of normal cells of N544 and N545, respectively. 


\section{Electron microscopic studies}

Strain N544 was incubated with PGY medium containing AF ( $50 \mu \mathrm{g} / \mathrm{ml})$, with and without phosphate. After $30 \mathrm{~min}$, samples were fixed and sectioned. Results are shown in Fig. $6(a)$ and (b). The control culture (Fig. 6e) was without the addition of AF or phosphate. We conclude tentatively that, in the presence of phosphate, the low electron density area spreads widely from the surface to the interior of cytoplasm. The cytoplasm contains granular aggregates, which are not seen in Fig. $6(b)$ and $(e)$.

With strain N545, the small granular aggregates were observed in both $\mathrm{AF}+$ phosphate Fig. $6(c)$ and $\mathrm{AF}$ alone Fig. $6(d)$, while such aggregation was not observed in the control culture Fig. $6(f)$.

\section{Plasmid instability to AF plus phosphate}

The $\mathrm{F}^{\prime}$ strain $\mathrm{N} 2025$ was inoculated into PGY media (pH 7.8) containing acridine orange ( $\mathrm{I} \mu \mathrm{g} / \mathrm{ml}$ ) and various concentrations of phosphate. Samples were withdrawn at intervals and plated on to BTB-galactose agar medium to score the number of colonies with and without the plasmid. Fig. 5 indicates that elimination of the plasmid is stimulated by the presence of high concentration of phosphate.

\section{DISCUSSION}

The results indicate that some but not all strains of E. coli $\mathrm{KI} 2$ are sensitive to AF+ phosphate, even when they are resistant to AF alone. Genetic analysis demonstrated that the strain specificity of the sensitivity to AF + phosphate was determined by a gene closely linked to lac. The gene is thought to be $a c r A$. Recently we found that the allele $a c r A^{+}$ directs biosynthesis of a protein constituent of the plasma membrane (unpublished data). It is therefore possible that the phenotype Acp- is a manifestation of a difference in this protein from that of the wild-type Acp ${ }^{+}$.

The effect of phosphate in stimulating the action of AF may be due to the formation of a complex between cationic $\mathrm{AF}$ and anionic $\mathrm{PO}_{4}{ }^{3-}$. The electron microscopic study suggests that, in the Acp cell, plasma membrane and the layer under it is disorganized by the presence of AF + phosphate but not by AF alone. These features resemble those of acrA mutant cells treated with AF (Nakamura \& Suganuma, 1972), suggesting that the primary action point of the AF-phosphate complex is the same as that of AF alone.

Finally, the closeness of $a c r A$ to the genes $p h o A$ and $p h o B$ (Taylor \& Trotter, 1972) is intriguing: phoA codes for enzyme alkaline phosphatase, and its expression is controlled by the regulator genes $p h o B$ and $p h o S$ together with inorganic phosphate (Echols et al. I96I; Aono \& Otsuji, 1968).

\section{REFERENCES}

Aono, H. \& OTsuJi, N. (1968). Genetic mapping of regulator gene phos for alkaline phosphatase in Escherichia coli. Journal of Bacteriology 95, I $182-1183$.

Echols, H., Garen, A., Garen, S. \& Torriani, A. (I96I). Genetic control of repression of alkaline phosphatase in Escherichia coli. Journal of Molecular Biology 3, 425-438.

Hirota, Y. (1960). The effect of acridine dyes on mating type factors in Escherichia coli. Proceedings of the National Academy of Sciences of the United States of America 46, 57-64.

Lennox, E. S. (I955). Transduction of linked genes of the host by bacteriophage PI. Virology I, I90-198.

NAKAmura, H. (1965). Gene-controlled resistance to acriflavine and other basic dyes in Escherichia coli. Journal of Bacteriology 90, 8-14.

NaKamura, H. (1966). Acriflavine-binding capacity of Escherichia coli in relation to acriflavine sensitivity and metabolic activity. Journal of Bacteriology 92, I447-I452. 
NAKAMURA, H. (1967). Changes in sensitivity to acriflavine of Escherichia coli grown in media of different glucose contents. Journal of General Microbiology 49, 443-449.

NaKAMURA, H. (1968). Genetic determination of resistance to acriflavine, phenethyl alcohol, and sodium dodecylsulfate in Escherichia coli. Journal of Bacteriology 96, 987-996.

NaKamura, H. (1971). Diagnosis of sugar utilization of Escherichia coli K-1 2 strains sensitive to acriflavine and other basic dyes. Japanese Journal of Genetics 46, 403-405.

NaKamuRA, H. (1974). Plasmid-instability in acrA mutants of Escherichia coli KI2. Journal of General Microbiology 84, 85-93.

Nakamura, H. \& Suganuma, A. (1972). Membrane mutation associated with sensitivity to acriflavine in Escherichia coli. Journal of Bacteriology 110, 329-335.

NaKamuRa, H., Tojo, H. \& GreenbuRG, J. (I975). Interaction of the expression of two membrane genes. acrA and plsA. in Escherichia coli K-I 2. Journal of Bacteriology I22, 874-879.

TAYLOR, A. L. \& Trotter, C. D. (1972). Linkage map of Escherichia coli Kr2. Bacteriological Review 36, 504-524. 